\title{
The Philosophical Exposition of the Mind of the Social Worker: Issues and Questions on the African Environment
}

\author{
Ani Casimir ${ }^{1}$, Ejiofor Samuel ${ }^{2}$ \\ ${ }^{1}$ Department of Philosophy/Institute of African Studies, University of Nigeria, Nsukka, Nigeria \\ ${ }^{2}$ Department of Social Work, University of Nigeria, Nsukka, Nigeria \\ Email: cepperngo@yahoo.com, ejorsamchi@yahoo.com
}

Received November 2013

\begin{abstract}
The philosophical penetration of the social work practice in Africa comes full cycle when a critical exposition of the contending issues and questions is carried out. Social challenges and problems in Africa make human suffering in the continent to be one of the highest in the world. An attempt to know the mind of the social worker in Africa reflects the issues of social work that dominate the African society. The mind of the social worker is perturbed by the problems of human suffering, poverty, societal stratification and conflicts, increasing gap between the rich and the poor, old-age problems, educational destitution, street begging, youth drug abuse, increasing religious terrorism and psychological instability of the elites. Posing these critical questions will reveal a lot about the mind and the psychological dispositions of the social worker in the African environment. The article seeks to reveal and expose these new questions as the platform for the search for the new psycho-socio-philosophical and integrative methodology that will solve the social problems of Africa in the 21st century.
\end{abstract}

Keywords: Social Worker; Mind; Social Philosophy; Human Values; Environmental Psychology; Africa in the 21st Century and the MDGs

\section{Introduction-Emerging from the Past of a Rich African Heritage of Colonial Socio-Cultural Challenges}

In this article, Africa is not being portrayed as a dark continent. That wrong impression is the propaganda of colonialists that started from the era of colonialism. This is an exposition of Africa by Africans for the benefit of Africans and their social development. An exposition of the mind of the social worker is a philosophical innovation that draws from the rich repository of wisdom found in social work and social philosophy. Bently (2012: p. 114) opines that the social worker operates in an environment where he is compelled to use his mind and principles of practice to alleviate human suffering and social challenges unique to his environment. It is important to take special note of the fact that the mind is a good reflector and mirror of the socio-cultural and natural worlds of man (Kanu, 2010). In other words, the mind reflects both the beauty and ugliness of man's environment. The philosophy of the mind is the precursor of man's state of mind and its contents. How the mind works, operates and behaves are studied either to know what the mind is (philosophy of mind) or how the mind affects or is affected by human behavior and his environment (Pyschology). There is a dynamic interplay between the mind of man, his behavior, his environment and his quest for social solutions to his social challenges (Ejiofor, 2010: p. 20). This portends that a psychosocio-philosophical approach must be applied by the social worker in Africa in studying the social problems he confronts in his professional work. This approach is another effective integrated theory of analyzing, exposing and solving emerging man-induced, social problems in Africa such as wars, refugees, poverty, drug addiction, internal displacement, homosexuality,
Hiv/Aids and the increasing population of un-served and destitute adults, youths, children and the infirm. The mind of the social worker in the African environment seeks to solve the social problems of Africa through an integrated approach of combining traditionalism with modernity in a unique sociophilosophic-psychological methodology that should constitute contemporary social work practice. The elements and dynamics of that contemporary practice we will seek to explore analyze and establish in the context of Africa's social work problems and environmental challenges.

\section{The African Social Environment: Issues and Challenges}

The African social environment today has not completed its colonial cycles, with the negative impacts of its colonial and neocolonial history still affecting individual as well as group development and growth. The European invasion (1844 Berlin wall sharing process) of the 1800s came with the wrong impression created by its colonialists that "Africa was a dark continent to be explored and exploited, having no relevant history or culture" (Kreizer, 2012; Hegel, 1956; Kuykendall, 1993; Pakenham, 1999). Correcting this deliberate and contrived error of history and culture are the following conclusions by Kreizer which challenges these errors and explains its dangers to the emergence of new scholarship and research by Africans in explaining and solving the social problems of Africans through indigenous knowledge systems and research sourced from data mined within the African environment:

The African continent has a rich and ancient history of which much has been forgotten and remains unacknowledged by the world today. With the expansion of European civilization into 
Africa came the assumption that Africa has no relevant history and culture. However, it is clear Africa had a long involved, complex and cultured history with immense diversity of ethnic groups living on a continent, complete with social, economic and political infrastructures. In terms of governance, Africa was probably more democratic than most other parts of the world, including Europe (Tandon, 1996: p. 296).

In situating the context of historical and cultural denial and affirmation of the authentic African personality and culture, Kreizer (2012: p. xviii) maintained that through these customs, laws, traditions and values, constitution and norms were derived and used to sustain stable African societies, using the example of Ghana pre-colonial society of West Africa wherein the "centre of the social system in precolonial West Africa was the kinship defined as the patterns of behavior associated with relatives in a society, together with the principles of governing these behaviors" (Nukuya, 1992: p. 11). According to Kreizer (2012), within the kinship system were religious and chieftaincy systems to administer the Division, look after the spiritual, physical, and emotional welfare of the people, maintain law and order, consult with elders, lead the army into battle, and act as mediator between ancestors and clans (Busia, 1951). Of particular note from this elucidation of traditional chieftaincy in Africa is the role played by the queen mother in the traditional social welfare scheme in Ghana.

With variations, such critical role of the traditional social worker, played by the queen mother in Ghana, for example, was given to different individuals and institutions in different parts of Africa: each king had a queen mother who watched the king's behavior, gave advice and counsel to him, and was involved in marriage considerations (Obeng, 1988). In this role, Rattray (1988) sees the role of the queen mother as that of whisper behind the stool; as the second most important person; her many roles within the community included community social wellbeing worker, distributor of local and governmental resources, liaison officer between people and the community support services, role model and care-giver for women and children, educationalist, guidance counselor, and supervisor of puberty rites, to name but a few (Boateng, 1982). It is unfortunate that this traditional system for social development and welfare established before the coming of European colonization was broken down with the colonization of Africa as observed by Kreizer (2012: p. xiv):

Colonization is relationship between people, groups, or countries where there is a domination and oppression of one particular relationship over the other resulting in what Freire (1997) calls the "culture of silence" in which a culture is so oppressed by another culture, they no longer have a voice in the society or the world and are therefore of no importance. The effect of this invasion on Africa was a loss of identity and culture that greatly affected the psyche of the people of Africa; through modernization, colonization favored western expertise and attempted to civilize Africa at the expense of its own knowledge and cultural practices...The hegemony of western knowledge influences all aspects of African life. There is strong desire to promote western knowledge, and to compete in a global world of universities that are on par with western university systems...This process promoted a dependency upon western material and often undermined local knowledge and expertise (Kreizer, 2012: p. xv).

Kreizer (2012) has gone further to trace the social problems of Africa today to this suppression of local knowledge and op- pression of African indigenous communities who supplied the raw materials and human resources for the development of the western societies that gave rise to globalization's cultural and economic superiority over Africa.

\section{Traditionalism and Modernity: Inclusion and Integration in Social Work Practice in Africa}

Africa is assailed with a lot of human suffering made endemic by poverty and other man-made variables such as bad governance, bad institutions, corruption and human greed. The overshadowing negative influence of colonialism and neocolonialism in creating the negative hegemonic environment and scholarship that gave rise to the underdeveloped mindset that produced vicious underdevelopment in the African state has been examined earlier in this article. The understanding of philosophy and social work constitute a good foundation for building the psychology and professional disposition of the African social worker towards contributing to the elevation of the standards of living and changing the lives of the poor and afflicted on the continent.

\section{Philosophy and Social Work: The Nexus}

Philosophy is concerned with the art of making meaning and sense of ourselves, our world and our social environment with its complexities. It compels the social worker to pose questions concerning Africa's social challenges such as why so much suffering, how can the suffering be changed and what are the best principles of social work that could be applied to transform lives in Africa. Asking these questions are necessary and relevant not only in revealing the social situation in Africa but also in exposing, on a daily basis, the assumptions which underlie the entire spectrum of theories that underlie the practice of social work in Africa. In social work, meaning is made of the human condition and the mind of the professional social worker applied in using that meaning to solve problems under social reality. Social work is a practical job, for according to Rengasamy (2012: p. 1):

As a practical job, it is about protecting people and changing lives, not about giving theoretical explanations of why they got into difficulties...social work is about social change at the individual as well as at community level. Change is complex, diversified and risk prone. To understand it the social worker needs knowledge, imagination, comprehensions and creativity... in short, a radical shift in understanding "knowledge as a process" as opposed to knowledge as product is needed".

Accordingly, only a paradigm shift in social work knowledge, understanding process and applications, in a unique and relevant dynamic approach, is what could solve Africa's complex emerging social reality and problems. The philosophical challenge is to juxtapose these definitional frameworks in the context of traditionalism and modernity while doing the needful to sift the wheat from the chaffs. Philosophy of social work should question these frameworks since it enables us to have the capacity to appreciate alternative perspectives in a variety of problematic and tiring of issues facing the social worker in Africa. A number of philosophical ideas and maxims stand the chance of influencing the different approaches to social work practice in Africa.

\section{African Philosophy, Personality and Human Values}

African philosophy has come to stay and be recognized as 
the indigenous philosophy reflecting the cosmology and ontology of the African personality (Okolo, 2001; Dukor, 2013: p. 43). Theistic humanism has come to be seen as the conceptual framework which confers global authenticity to the human values of truth, righteousness, peace, (non-violence) compassion and love that define the essential nature and personality of the African mind. God is seen as a factor that guides the African in all aspects of his life and relationship with others. These human values were deified and globalized by Sathya Sai Baba (1954: p. 104) in the ground breaking "education in human values” (EHV) concept in educational curriculum, content and new educational school models that led to the foundation of the African Institute for Education in human values (TAISSE, 2005) and equally informed the backbone of its educational philosophy and practice. A social work practice from an African personality is operated by an African mind that is permeated with a theistic and humanistic human values, ethics and principles. Accordingly, Paine (1997) argues that social work theory succeeds best when it contains all three elements of perspective, theory and model with a steady stream of culture defined human values since the way of perceiving the world flows from a value (of the social worker). If one wants to know about the values cherished and honored by the social worker, we should make effort to know what the social worker does, in brief. Have you ever wondered what social workers do? The answer to this question gives us some insight into social work practice and the theory which informs the practice. It also enables us to be introduced to the four components to good practice and appreciate the importance of the following approaches to social work practice and how to relate to human values and social needs:

- Biography

- The social context of social work

- Responding to children's needs

- Empowerment and advocacy in social work

- Social work purpose, roles, codes and standards

While these five may constitute only few of the many approaches that define the content of social work, they are contained within the philosophical consideration of new knowledge that could be generated from the four components. This philosophical exposure gives us a flavor of what social work is about and encourage you to explore further so as to summarize the four components of good practice to enable us to have better insight into what constitutes human value and the extent societal values play in influencing the mind of the social worker, especially when it comes to his cultural environment of practice. Every good practice of social work is always informed and guided by human values in a cultural context (Banks S., 2001). The four components of good practice are introduced here and we find references to them throughout the career of a social worker as he learns, practices and researches on best practices that could solve the complex social problems troubling the African society. The four components are:

- Knowledge

- Skills

- Values and Ethics

- The Social Work Process

It is critical that we appreciate the fact that each of the unit draws upon and illustrates the application of the four components of good practice in a mutually inclusive manner. Let us take the knowledge component, for example. Four main perspectives inform this second edition. First, the view that in order to be effective, social work practitioners must work from a sound knowledge base, that is, one that is relevant and identifiable. A second perspective sees social work as essentially a "capacity building" activity: a perspective that emphasizes the important role that social workers can play in terms of enhancing individual, family, group and environmental capacities. A third perspective recognizes that social work is very much about relating: about the benefits and limitations that people experience in their relationships with others. The importance of the capacity to relate can be seen in the way that people relate to themselves, others and to society. It is here that people sometimes turn to social work, and to other professions, for help to address the difficulties they are experiencing. The capacity to relate can be identified most visibly in the way people communicate, which leads to the fourth perspective on the importance of communication skills within social work. Although these perspectives are described under separate headings, they overlap and interweave in ways that are multifaceted and intricate but which together provide a basis for a more coherent practice framework.

\section{The Importance of a Sound Knowledge Base}

In order to acquire and to perfect a "toolbox" or "basket" of practice skills and interventions, we need to have a sound knowledge base from which to begin to understand people and their situations and to formulate plans of action appropriate to the circumstances encountered. This involves understanding how experience are perceived, understood and communicated by people, and how this impacts on behaviour and life situations, always be incomplete and uneven because, in the realm of human experience, life is unpredictable and some uncertainty is inevitable (Marris, 1996a). This complexity is acknowledged by the General Social Care Council (GSCC) and the National Occupational Standards (NOS) and by other influential bodies within social work:

Social work in its various forms addresses the multiple, complex transactions between people and their environments. Its mission is to enable all people to develop their full potential, enrich their lives, and prevent dysfunction. Professional social work is focused on problem-solving and change. As such, social workers are change agents in society and in the lives of the individuals, families and communities they serve. Social work is an interrelated system of values, theory and practice (IASSW/ IFSW, 2001).

Central to this purpose is the development of skills and interventions that are capable of influencing "people and their environments". This can be a formidable task and an area where no profession or practice approach can claim complete success, a point emphasized in discussion document from the Prime Minister's Strategy Unit at the Cabinet Office, entitled Personal Responsibility and Changing Behaviour: The state of Knowledge and its Implications for Public Policy:

This paper has set out a body of theories, evidence and possible policy applications. The field remains relatively underdeveloped. Many more policy makers are familiar with economic principles or law than with psychology. There have been few attempts to pull together the knowledge base in a systematic way, and policies to influence behavior are often ad hoc... Looking to the future there is an evident need to strengthen our theoretical and empirical understanding of what drives behavior and behavioral change... Policy should not simply proclaim personal responsibility or blame, but needs to be shaped around 
the ways in which people actually think and feel, and the social and psychological forces that influence behavior. (Halpern \& Bates, 2004: p. 67).

We can continue to extend our knowledge through research but we still need to be able to "pull together" and use what we know. It is interesting to note that this discussion document covers a wide range of social problems and includes several professional groups, such as teachers, nurses and doctors. However, social work and social workers are not mentioned and this is happening more and more in relation to documents of this kind. Yet perhaps more than any other profession, social work has a long history and a great deal of experience in the area of helping people with limited resources to change their lives, and has an extensive library on this subject. Social work's particular contribution in the field of social welfare and social change lies in the fact that practitioners work with people from some of the most deprived and disadvantaged sectors of the population and, as a result, we have developed specific knowledge, skills and understanding from the concentrated work we continue to perform in this area. A further contribution lies in the way that our values shape our work-a perspective that embraces the importance of social justice.

This value perspective is most evident in the way that we communicate with service users, careers and others, as well as in the "attitudes, methods and practices of practitioners and their agencies" (Clark, 2000: p. 360). According to the status that certain groups hold within society, the right to social justice can be threatened and lead to prejudice and discrimination. These injustices can be based on an individual's class, race, gender, age, disabilities, sexual orientation, religious/spiritual beliefs, culture, health and geographic location (such as the divisions that exist between the north and south of England), or simply on the fact that some people are poor and behave in ways that reveal their lack of life chances and social exclusion. Social work is not unique in its values perspective, but other professions may not have given this issue the same importance, although the picture is changing. For example, in recent years there has been considerable coverage on the impact of poverty and deprivation in relation to health in the British Medical Journal (Watt, 2001: pp. 175-6) and Lancet (Horton, 2002: p. 186).

For any knowledge to be valuable in social work, it has to be relevant and applicable to the issues regularly encountered in practice. On the other hand, practice also needs to inform knowledge - and in an ongoing way-through conceptualizing what we do in ways that revise existing theories where they are at odds with the experiences of practice. However, too often the knowledge generated from practice is not written up and published, which means it is not available for other practitioners, and other professionals, to use and to develop further. The view held by a number of practitioners and academics is that the world of theorizing and writing, "belongs" to the realm of academics. Although not intended, the introduction of an evidence based perspective in social work has had the effect of eroding some practitioners' confidence in relation to the knowledge and theory base of social work practice. This is a worrying development and one that needs to be addressed.

Knowledge is colored by values and ethics; knowledge deepens skills and hones the process of delivery while good practice comes only from an integration of the whole in a culturally relevant and human value context.

However, in the context of the special tasks we have as- signed to our research in this paper, we are further compelled to pose the question: What are social work values?

Traditionally, one of the things that distinguishes a professsion is that it has a set of principles to which its members have to be committed and must put into practice. Sarah Banks defines social work values as:

A set of fundamental moral/ethical principles to which social workers are/should be committed (Banks, 2001: p. 6). Values and ethics empower the social worker to appreciate the following professional engagement morals and keep his mind well focused upon delivery and alleviation of human suffering (Trevithick, 2010: p. 292):

a) Awareness of your own values, prejudices, ethical dilemmas and conflicts of interest and their implications on your practice

b) Respect for, and the promotion of:

- Each person as an individual

- Independence and quality of life for individuals, whilst protecting them from harm

- Dignity and privacy of individuals, families, careers, groups and communities

c) Recognize and facilitate each person's use of language and form of communication of their choice

d) Value, recognize and respect the diversity, expertise and experience of individuals, families, careers, groups and communities

e) Maintain the trust and confidence of individuals, families, careers, groups and community by communicating in an open, accurate and understandable way

f) Understand and make use of strategies to challenge discrimination, disadvantage and other forms of inequality and injustice

The British Association of Social Workers issued a revised Code of Ethics for Social Work in April 2002. This emphasises that social work is committed to five basic values:

- Human dignity and worth

- Social justice

- Service to humanity

- Integrity

- Competence

(BASW, 2002: p. 2)

The Code discusses each value and derives from them principles that should guide a social worker's conduct, wherein the code emphasizes the value personality, identity and social justice in a cultural context which mixes the human values found in the practitioner and clients environment with the professional code:

David Howe (1999) advises that values are important because they help to guide action. However, they are not without their difficulties, because, he suggests, values spell debate and trouble. He outlines two types of values: "intrinsic values", which are good in themselves (for example, personal wellbeing); and "instrumental values", which are linked to ends (for example, laws which uphold rights). Social workers bring their individual values but also recognize institutional and professional values. These can potentially be in conflict but must be resolved. We are acutely aware that we cannot "teach" the values required by the Social Work Degree framework documents without looking at the context in which you work, and the changes that are taking place in social work. The establishment of new ways of delivering social services, particularly the "purchaser-provider" split, and the increasing privatization of ser- 
vices, are as much a part of this context of work as those aspects that represent continuity in social work, for example the "social work relationship" with the service user, or seeing social work services as there to "help" people. If we have to generalize, then it is probably true to say that the fundamental value we promote is one of social justice, backed up by respect for each person's “identity". At the same time we have to take account of the world in which we live, and the changes that impinge on the delivery of services to people. If the human "values" of social work are to mean anything, then we should spell out what we think they mean in practice. What kind of values should permeate the mind of the Africa social worker and duly inform his knowledge and practice in a cultural context? Should he just re-echo global western values of social work or innovatively strive to be relevant in a culturally creative and theoretical manner?

To my mind, what the values mean in practice should be interpreted in the context of the socio-cultural, psychological and philosophical context of the African social worker. In essence, the African personality of the social worker is influenced by the human values of African philosophy to analyze, understand, sympathize and help the condition of his fellows towards achieving personal and community transformation and betterment of lives. The profession has been influenced by these factors, with a dependency on western social work education and practice. The challenge started back in the 1970s with the ASWEA conferences, to critically think through what social work education means in an African context and this was just the beginning. This issue continues today and is more relevant than ever. This book is written mainly for African social workers and academics in hopes that, through reading his book, a spark of revolutionary thinking is ignited as to what kind of social work education and practice would be most useful and practical for Africa in the twenty-first century. Mobilizing relevant people in order to go through this process of examining assumptions, critiquing and building cultural relevant social work curriculum is both difficult and creative. To remove one's self from western knowledge that has been deemed "the best", and held in high esteem, is to ask a culture to remove itself from its parent and start a new life on its own. Taking the best of the western theory and practice and practice and balancing it with African indigenous knowledge and traditions is an important step in this process. This is the only way that African social work can be a creative and revolutionary force in Africa and in social work worldwide (ASWEA, 1974c: p. 32).

In supporting this need for a culturally relevant social work principle and practice in Africa in the context of our new framework, the project relishes the apt observations of Kreiberk why the search for certainty in social work theory and practice remain conclusive:

Why has it been so difficult to cut the umbilical cord of western social work training and practice for a more cultural relevant social work education program for Africans? Whey, after sixty years of social work in many countries in Africa is the profession still struggling and still on the periphery?

The African social worker, to succeed in his career of transforming lives, must imbue and embed his professional practice with the communal values of the African philosophy and personality to have a mind and psychology of environmental and social transformation and betterment of human suffering. This enables him to scientifically isolate some theories of social work and adopt new ones that reflect African human values.
The essential peculiarity of these African values empowers the content of the social worker's creative approach, perspective and theory that will define the new model proposed as an innovative social work practice that responds and understands the problems and mindset of the victims of social injustice in Africa.

\section{Immanuel Kant's Categorical Imperative}

One of the most potent Western philosophical principles that could positively influence social work practice through the mind of the social worker in Africa is Immanuel Kant's categorical imperative. Through his classical work entitled, "groundwork for the metaphysics of morals", he came up with his humanity or end in itself formulations. Therein, Kant observed thus: "Act in such a way that you always treat humanity, whether in your own person or in the person of any other, never simply as a means, but always at the same time as an end” (Kant: compilations: p. 223).

In relation to social work, this Kantian concept could be applied in the context of any new child protection legislation, policy or practice in any African country. In the light of emerging and increasing marital conflicts, divorces, separations between husbands and wives the social worker is heavily pressured by both sides to take decisions from the selfish interests of either of the two parties at the detriment of the child or children. In the context of the Kantian positive influence on the mind of the social worker, even though he should not view or treat the parents as means to meeting their children's ends, the social worker reflects on how best to achieve the welfare, protection and future of the children. This means that extant child protection legislation and policies in Africa should think first of the welfare of the child as paramount consideration when the objectives of these social work legislations and policies are drawn up by the managers of the social welfare programs in Africa. When equally, the African social worker is called upon to decide such cases involving children and their feuding parents, he is required to make decisions regarding children's education, upbringing, training, protection and psychological stability-this means that the social worker is required to be childvalue sensitive in an African cultural manner. A mean should be drawn between the end of achieving the children's welfare and the requests of the divorcee parents. Thus the Kantian imperative is a social value that mirrors the African social value of putting the interests of others before self' reflected in communalism which goes further to see the child as a community wealth and property which must be protected just as the future of the community is well protected by a social practice of human values.

\section{Traditionalism and Social Work}

The traditional definition of social work known to scholars in the Western world and neo-colonial Africa sees it as a professional calling and activity that helps, assists and enables people in changing their lives by helping themselves. The impression given here is that social work is a faultless, peaceful, and noncontradictory process without challenges per se (PD Mishra, 1994). This fails to capture the complexities and transformations which social work has undergone throughout the world of its practice and, certainly, the tumultuous social, political, cultural and economic environment faced by the social worker in Africa. It also fails to underpin the cultural and philosophical 
transformation going through the mind of the social worker as he grapples with the challenges thrown up by his environment in the 21st century as Africa seeks to build a new framework for social work practice after colonialism and neocolonialism. Under this western conception we could give a traditional view defined in the manner that captures the practice perspectives of Pamela Trevithick:

The legal, social, economic and ecological context of social work come mainly from:

g) Country, UK, EU legislation, statutory codes, standards, frameworks and guidance relevant to social work practice and related fields, including multi-disciplinary and multi-organizational practice, data protection and confidentiality of information

h) Social policy, including policy on social care, criminal justice, education, health, housing, income support

i) Demographic and social trends

j) Theories of poverty, unemployment, health, impairment and other source of discrimination and disadvantage and their impact on social exclusion

k) Policies on diversity, discrimination and promoting independence/autonomy of adults, children, families, groups and communities, and research on their effectiveness

The context of social work practice for this area of work for this article shall concentrate and work upon:

l) Historical perspectives of social work and social welfare

m) International law and social policy, in broad terms, for the purpose of comparison

n) Contemporary issues and trends in social work

o) Understanding of why people use social work and social care services

p) Psychological and sociological explanation of:

- Human growth and development and the factors that impact on it

- Mental health and well being

- Social interactions and relationships

- Discrimination and oppression

- Human behaviour

q) Knowledge of the range of local resources and services

r) Theories about how systems work

s) Organizational structures, policies and procedures for referral

t) Policies, procedures and legal requirements for the security and confidentiality of information

u) How to access and use information and communications technology (ICT) and other electronic systems that may help in the collection of information

As we can see there is an existing tension between view and the African emerging view sought by this article. The environment of poverty and the persistence of suffering by the poor, despite the application of Western concepts of social work and poverty alleviation means that something new must come that is unique to the African social environment, mirrored by poverty in Nigeria (Onokola, 2003). This is the dilemma of traditionalism and modernity in Africa. It is the jinx of continuing an old palliative to seek an end to a social problem when that situation calls for a new cultural mix that truly captures the reality of the social challenge. This dilemma is well enunciated by Rengasamy (2012: p. 6) in the following lucid philosophical questions:

What is the need of social work or why social work? Which definitions work today? How is social work carried out? To whom is social work going to save or what are the characteristics of its clients. To answer these questions one need to know why people are suffering. What are our responsibilities towards follow human beings? How we gain knowledge about the human problems? What makes us perceive the human problems in a particular way? Why we subscribe to certain methods of solving problems... Social workers need to answer these questions before addressing others' problems. Theories and perspectives of social work may provide some answers to these questions.

\section{Modern Social Work Philosophies and Theories}

A philosophy is a world view, theory or assumption that seeks to explain reality or a situation. A social work philosophy or theory is in a class of its own as it seeks to explain why, what, when, where and how of a social or individual challenging problem. Not all social work theories would pass this muster in the African context since most are based upon an European would view or assumption of how societies should be organized. Thus since there exists uncertainty about some of such theories, the explanation by Cotted (2081) that sees theory as a set of ideas that helps to explain why something happens or happened in a particular way, and to predict likely outcomes in the future... but not yet conclusively proved' may give us further support of the incongruity between European and African theories of social work.

Social work theories, models and methods for working with individuals, families, careers, groups and communities embody the following schema of operational practice:

a) Principles, theories and methods of social work practice

b) Theories about the impact of authority and power in the social work role

c) Theories about the impact of discrimination, and methods of working with diversity

d) Theories and methods about working with the main groups of people using service. These include childcare, mental health, learning difficulties, older people, minority and ethnic groups, drug and alcohol use, disability and impairment

e) Principles about balancing the rights of individuals, families, careers, groups and communities with the interests of society and the requirements of practice

f) Lessons learned from both serious failure of service and practice, and from successful interventions

v) Approaches to evidence and knowledge based practice

w) Theories of organizations, group behaviour and organizational change

$\mathrm{x})$ Theories and methods of promoting personal, social and emotional well being (NOS, 2004: p. 20)

When one zeros in on the theories of social work, the necessity of benchmarking a theory of social work on its successful practice, for example, in Africa, comes to mind with the definition of theory given by Bachet (1995): a set of ideas or principles used to guide practice which are sufficiently coherent that they could if necessary be made explicit in a form which was open to challenge!!

Thus theories as philosophies, should have the power to explain issues, events, circumstances and challenges unique to a particular society's cultural environment such that marries the theories of individual/group behavior with the values of personalities, professional models, views or theories of social work in its successful alchemical mix. With a good dialectical and chemical marriage, social work practice in Africa should serve 
and achieve the objectives of socio-cultural and economic transformation and empowerment of individual and community lives on the continent. Secondly, they should make provision for new theoretical inputs to the social work knowledge-base, research and practice in Africa. Thirdly, they should embody the values and principles drawn from African philosophy and the African mind of the social worker engaged in daily practice.

When structured in that culturally dialectical and alchemical process, African social work theories will serve the profession of social work and solve the problems in the African environment in accordance with the classical objectives elucidated by Regasamy (2013: p. 4), who opined that sound social workers though use theory to understand and explain three main aspects of social working:

a) The task and purpose of social work-the role of social work in society

b) Practice theories: sometimes called social work approaches or methods - how to go about doing social work

c) The world of service users, including the internal (Psychological) world and the external (social) world

Thus we can see that good theories of social work focus on the profession, its purpose, domain and character in particular societies. In this context, they should explain human behavior, the social environment, the cultural values and why change happens in that environment. Managing change in unique socio-cultural environments such as in Africa can be well explained and facilitated by the African social worker who has used his African mind to study, analyze and understand the human values peculiar to the African social environment. Through these values as guiding pillars to his social work practice, he will not fail to come up with orientational, explanatory or practical theories that embody the integration of the old and new in a dynamic problem-solving manner. This calls for and justifies this article's research objective of working towards the deconstruction, reconstruction and construction of a new social work cultural principle within the context of the socio-philosophic-psychological framework.

The socio-philosophic-psychological methodology designs a new template for social work practice and framework that takes note of the African value perspective with an eye of generating innovative systems that combines the new and old of the bestlowing historical and environmental peculiarities of Africa:

1) The mind and personality of the African social worker, agitated by global social problems, is more concerned with the endemic social problems of human suffering in the continent;

2) The mind of the African social worker structured with evolving new integrated dynamic practical approaches/theories that seeks to solve these identified problems in a sustainable and multi-disciplinary manner;

3) The mind of the social worker is committed to evolving as well a new social scholarship through new research that challenges the limited strictures of the old colonial scholarship of social work which is out of congruence with the challenging social realities in Africa and fails to encode Africa's cultural values and cosmology as workable social work principles as school curriculum and professional practice;

4) This new social work scholarship, research and practices that embeds Africa's human values combines traditionalism and modernity in its best traditions in an inclusive and integrated approach that seeks to manage Africa's environmental and social challenges in the context of the Millennium development Goals(MDGs).

\section{Recommendations on Charting a New Social Work Practice}

As analyzed in this article, the unique socio-philosophiopsychological approach to successful social work practice recognizes the three core influential frameworks for practice. They take into consideration the uniqueness of Africa's ecosystem, Africa's internal coping strategic strengths and the continent communal and cultural competence. These three perspectives made lucid by both S. Rengasmy (2013) and Army (1991: p. 74) could be quoted below as reflectors of the emerging African inclusive theories of social work practice:

\section{The Ecosystem Perspective}

This perspective focuses on the interplay between the person and his environment. To understand the functioning of the individual, we must understand his or her environmental context.

1) Families exist within communities and neighbourhoods;

2) Individiuals, families, and neighbourhoods exist in a political, economic and cultural environment;

3) The environment impacts the actions, beliefs, and choices of the individual.

\section{The Strengths Perspective}

This perspective is built on the assumption that every individual, family, group and community has strengths and focusing on these thoughts leads to growth and overcoming of difficulties. Under this perspective, clients are generally the best experts about what types of helping strategies will be effective or ineffective.

\section{The Cultural Competence Perspective}

This perspective is the understanding and approval of cultural distinctions, taking into account the beliefs, values, activities and customs of distinctive population groups. Many cultures have prescribed ways of talking about health and the human body and these factors impact a person's reaction and acceptance of health services.

These perspectives could be embodied and used as the recommended philosophical framework to establish the content of the new and unique Africa's philosophic-socio and psychological social work theory through the following action plans.

1) Setting a new research centre in Africa to outline the content of a new social work practice;

2) Organize and establish a new scholarship data base to aggregate data relating to new framework and actual social work practice in African countries;

3) Set up global cultural centers of social work that could provide observation, description, explanation, prediction and successful social work interventions in Africa, India, China, and other cultural environments emerging or have emerged from colonial theoretical impositions;

4) Work with United Nations/regional bodies such as UNESCO to establish culture as a necessary component of social work practice

\section{Conclusion}

Many historical and current factors have influenced how the 
profession of social work has emerged in Africa. From a continent with a long and convoluted history made up of mininations (Maathai, 2009) to a continent colonized but on the upward climb to modernize, Africa has experienced more than its share of political, economic, and social challenges (Yimam, 1990). Why has the re-examination of social work education in Africa, completed through the ASWEA conferences, been slow to take hold? Africa is re-emerging as an important force in the world order. Social work can play an important role in this re-identification process. However, in order to do this it first has to cleanse its own self from past indoctrination by others. Critical analysis of the curriculum in light of colonization and modernization and globalization is a possible next working step. Through the processes, the social work profession can create culturally relevant social work training and practice that fits its own needs as a continent. A new and creative curriculum will emerge when African social workers and academics question and take charge of their own training and practice. The time has come for Africans to have partners and not masters. This calls for a relationship of solidarity (Kreitzer \& Wilson, 2010).

We have made the point that the arguments of theoretical innovation, adaptation, change, inclusion and integration between the traditional and modern theories, philosophies and methods of social work practice would succeed more in Africa because they embody the possibility of designing unique and relevant environment approach of solving the social challenges confronting him in his environment. While recognizing all the major theories used in social work practice, such as systems, psychodynamic, social, conflict feminist, problem solving task centered, solution focused cognitive behavioral, crisis based, narrative theories, this article has isolated the cultural strengths and the eco-systems approaches as perspective that could help the mind their African social worker to grapple with the emerging social challenges and empower Africans to help themselves in a human-value sustainable manner in the 21 st century.

\section{REFERENCES}

ASWEA Conferences (ASWEA, 1974c: p.32).-_Aimed at removing one's self from western knowledge that has been deemed "the best", and held in high esteem, is to ask a culture to remove itself from its parent and start a new life on its own. Taking the best of the western theory and practice and practice and balancing it with African indigenous knowledge and traditions is an important step in this process. This is the only way that African social work can be a creative and revolutionary force in Africa and in social work worldwide.

Baba, S. S. (1954). The five human values, the human personality and god. Andra Pradesh: Prasanthic Press.

Banks, S. (2001). Ethics and Values in social work (2nd ed.). London:
BASW/Macmillan.

Bently (2012). Social work practice in mental health: Contemporary roles, tasks, and techniques mental health practice. Brazil: Amazon.

Bettmann, J. E., Jacques, G., \& Frost, C. J. (2012). International social work practice: Case studies from a global context. London: Routledge.

Bonoti, F., \& Metallidou, P. (2010). Children's judgments and feelings about their own drawings. Psychology, 1, 329-336. http://dx.doi.org/10.4236/psych.2010.15042

British Association of Social Workers (BASW) (2002). Code of ethics for social work.

Dalrymple, J., \& Burke, B. (1995). Anti oppressive practice and the law. Buckingham: Open University Press.

Dukor (2013). Theistic humanism. Germany: Lambert publishers.

Ejiofor, S. (2013). Social work theory and practice in Africa: The challenge of sustainable poverty reduction. Nigerian journal intellectual property and humanities (NIPO). Nigeria: CEPPER Press.

Freire (1997). The politics of education: culture, power, and liberation. South Hadley: Bergin \& Garvey.

Freire, P. (1970). Cultural action for freedom. Cambridge: Harvard Educational Review.

Freire, P. (1970). Pedagogy of the Oppressed. New York: Continuum.

Freire, P. (1973). Education for critical consciousness. New York: Seabury Press.

Freire, P. (1975). Conscientization. Geneva: World Council of Churches.

Freire, P. (1976). Education, the practice of freedom. London: Writers and Readers Publishing Cooperative.

Freire, P. (1978). Pedagogy in process: The letters to Guinea-Bissau. New York: The Seabury Press.

Howe, D. (1999). Values in social work. In M. Davies, D. Howe, \& R. Kohli, Eds., Assessing competence and values in social work practice. Norwich: Social Work Monographs.

Kant, E. (2000). The categorical imperative-An ocean of spiritual resources. Lexighton: Catholic Ecyclopeadia.

Kanu, K. (2010). The mind and the personality of the African-A human value perspective. Ndola: TAISSE Press.

Kuykendall (1993). Deviance and corruption: Typology of police deviance. London: Pakenham.

Okolo, B. (2001). Philosophy and nation building in Nigeria. Onitsha: Caritas Press.

Onokola et al. (2003). Environment and poverty in Nigeria. Nigeria: Jamoe Entreprises.

Payne, M. (1997). Modern social work theory (2nd ed.). London: Macmillan Press Ltd.

Swartz, L., Rohleder, P., Bozalek, V., Carolissen, R., Leibowitz, B., \& Nicholls, L. (2009) Your mind is the battlefield: South African trainee health workers engage with the past. Social Work Education, 28, 488-501.

Tandon (1996). Professional writing for social work practice. London: Amazon.com.

Trevithick, P. (2010). Social work skills-A practice handbook (2nd ed.). New York: Open University Press.

Walker, J., \& Crwaford, K. (2010). Glasgow: Learning Matters Ltd. 